\title{
Requirement for a standardised definition of advanced gastric cancer
}

\author{
ANGELO DE SOL ${ }^{1}$, STEFANO TRASTULLI $^{2}$, VERONICA GRASSI ${ }^{2}$, ALESSIA CORSI $^{2}$, IVAN BARILLARO $^{2}$ \\ ANDREA BOCCOLINI $^{2}$, MICOL SOLE DI PATRIZI ${ }^{2}$, GIORGIO DI ROCCO ${ }^{3}$, ALBERTO SANTORO ${ }^{3}$, \\ ROBERTO CIROCCHI ${ }^{2}$, CARLO BOSELLI $^{2}$, ADRIANO REDLER $^{3}$, GIUSEPPE NOYA $^{2}$ and SEONG-HO KONG ${ }^{4}$ \\ ${ }^{1}$ Department of General Surgery, University of Perugia, St. Maria Hospital, Terni; \\ ${ }^{2}$ Department of General and Oncological Surgery, University of Perugia, Perugia; ${ }^{3}$ Department of Surgical Sciences, \\ Sapienza University of Rome, Rome, Italy; ${ }^{4}$ Department of Surgery, Seoul National University College of Medicine, \\ Seoul, Republic of Korea
}

Received February 25, 2013; Accepted August 23, 2013

DOI: $10.3892 / 01.2013 .1672$

\begin{abstract}
Each year, 988,000 new cases of stomach cancer are reported worldwide. Uniformity for the definition of advanced gastric cancer (AGC) is required to ensure the improved management of patients. Various classifications do actually exist for gastric cancer, but the classification determined by lesion depth is extremely important, as it has been shown to correlate with patient prognosis; for example, early gastric cancer (EGC) has a favourable prognosis when compared with AGC. In the literature, the definition of EGC is clear, however, there is heterogeneity in the definition of AGC. In the current study, all parameters of the TNM classification for AGC reported in each previous study were individually analysed. It was necessary to perform a comprehensive systematic literature search of all previous studies that have reported a definition of ACG to guarantee homogeneity in the assessment of surgical outcome. It must be understood that the term 'advanced gastric cancer' may implicate a number of stages of disease, and studies must highlight the exact clinical TNM stages used for evaluation of the study.
\end{abstract}

\section{Article}

At present, stomach cancer is among the most common malignant neoplasms, with $>988,000$ new cases reported worldwide each year (1). However, incidence rates are markedly decreasing (2) with variations in the geographical distribution and the anatomical localisation of the disease in the various regions of the intestines $(3,4)$. The highest incidence rates to date are in Japan and other East Asian countries, including

Correspondence to: Dr Alessia Corsi, Department of General and Oncological Surgery, University of Perugia, S. Andrea delle Fratte, Perugia 06156, Italy

E-mail: alessia.cor@libero.it

Key words: Japanese Gastroenterological Endoscopic Society, early gastric cancer, advanced gastric cancer, stomach cancer
Korea and certain regions of Japan. In addition, a number of Latin American populations are also at high risk of developing the disease, including those of Chile and Costa Rica. With regard to Europe, the highest mortality and incidence rates are observed in Hungary, Finland, Austria and Iceland (5).

Carcinoma of the stomach represents the fifth most common cause of cancer-related mortality in Western populations, despite its decreasing incidence in Europe and the United States. Gastric cancer is rarely detected $(\sim 8 \%)$ in the form of early gastric cancer (EGC) during the mildly symptomatic or asymptomatic phases. In the majority of patients, gastric cancer is diagnosed at a later stage than the first stage of disease progression (6), with classic symptoms of weight loss, consistent and dull pain in the epigastrium, loss of appetite, nausea, vomiting and chronic bleeding $(7,8)$. Rare symptoms of disseminated gastric cancer manifest as renal colic (9). In Europe, gastric cancer represents 8-9\% of newly diagnosed cancer cases, and incidence and mortality are twice as high in males compared with females. The highest incidence rates occur in Portugal, Italy, Germany and Spain (10). Various methods of pathological classifications exist for stomach cancer, including microscopic (11), macroscopic (12), biological behaviour $(13,14)$ lesion depth [these are ECG and advanced gastric cancer (AGC)] and TNM classification (Table I) (15).

The classification determined by lesion depth is extremely important as it has been shown to correlate with patient prognosis; for example, EGC has a favourable prognosis when compared with AGC (16). EGC refers to those adenocarcinomas with growth that is limited to the mucosa or submucosa, independent of regional lymph node (LN) metastases (17). According to the Japanese Gastroenterological Endoscopy Society (18), EGC may be further classified based of the macroscopic aspect of the neoplasia into three main types, $0-\mathrm{I}$, 0 -II and 0-III, of which, type 0-II has three subtypes, 0 -IIa, b and c (15). The characteristics of these types are as follows: i) 0-I (protruding), polypoid tumours that protrude above the mucosa surface $>3 \mathrm{~mm}$; ii) 0 -II (superficial), tumours with or without minimal elevation or depression relative to surrounding mucosa. Specifically, 0-IIa (superficially elevated), slightly elevated tumours that thicken the mucosa to 
Table I. TNM classification.

\begin{tabular}{|c|c|}
\hline Classification & Description \\
\hline \multicolumn{2}{|c|}{$\mathrm{T}$, size and extent of the tumour } \\
\hline$X$ & Depth of tumour unknown \\
\hline 0 & No evidence of primary tumour \\
\hline 1 & Tumour confined to $\mathrm{M}$ or $\mathrm{SM}$ \\
\hline $1 \mathrm{a}$ & Tumour confined to $\mathrm{M}$ \\
\hline $1 b$ & Tumour confined to SM \\
\hline 2 & MP tumour invasion \\
\hline 3 & SS tumour invasion \\
\hline 4 & Tumour invasion contiguous to or exposed beyond SE/SI \\
\hline $4 \mathrm{a}$ & Contiguous to or penetrates SE and PERC exposure \\
\hline $4 b$ & SI invasion \\
\hline \multicolumn{2}{|l|}{$\mathrm{N}, \mathrm{LNs}$} \\
\hline $\mathrm{X}$ & Regional LNs cannot be assessed \\
\hline 0 & No regional LN metastasis \\
\hline 1 & Metastasis in 1-2 regional LNs \\
\hline 2 & Metastasis in 3-6 regional LNs \\
\hline 3 & Metastasis in $\geq 7$ regional LNs \\
\hline $3 a$ & Metastasis in 7-15 regional LNs \\
\hline $3 b$ & Metastasis in $\geq 16$ regional LNs. \\
\hline \multicolumn{2}{|c|}{ M, distant metastasis } \\
\hline $\mathrm{X}$ & Distant metastasis status unknown \\
\hline 0 & No distant metastasis \\
\hline 1 & Distant metastasis \\
\hline
\end{tabular}

Japanese Classification of Gastric Carcinoma [3 $3^{\text {rd }}$ English edition (10)]. M, musoca; SM, submucosa; MP, muscularis propria; SS, subserosa; SE, serosa; SI, adjacent structures; PERC, peritoneal cavity.

$<3 \mathrm{~mm}$ in thickness; 0-IIb (superficially flat), tumours without elevation or depression; and 0-IIc (superficially depressed), slightly depressed tumours; and iii) 0 -III (excavated), tumours with a deep depression.

The average time between EGC diagnosis and progression is $\sim 37$ months (19) and it commonly takes 8 months for EGC to progress to an advanced stage of disease. The percentage of EGC cases reported in Japan is higher (30-50\%) compared with Western countries (5-15\%), where screening programmes have not been implemented (20). For example, in Korea the proportion of $\mathrm{T} 1$ and N0 tumours was demonstrated to increase gradually with time, from 24.8 to $41.3 \%$ in period 1 (1986-1990) and from 48.9 to $58.6 \%$ in period 4 (2000-2006; both $\mathrm{P}<0.001)(21)$. The importance of correctly identifying EGC is highlighted by its correlation with the excellent results achieved by surgical treatment and the favourable prognosis of EGC patients following surgery.

The survival rate following surgical resection is $70-95 \%$ depending on LN involvement. Therefore, it is extremely useful to understand the involvement of LNs prior to surgery. However, there is no simple, high sensitivity test available to evaluate LN status pre-operatively. The present diagnostic imaging techniques remain unsatisfactory, however, double contrast-enhanced ultrasonography shows promise as a new, non-invasive, convenient and reproducible method for the evaluation of LN metastasis in EGC and the prognosis of EGC pre-operatively. The identification of EGC by marked hyperenhancement allows for closer post-operative follow-up and possibly the use of drugs for the targeted growth of new vessels to prevent recurrence (22).

Macroscopic classification is of extreme prognostic relevance, therefore, it is fundamental to standardise the definitions of EGC and AGC. The definition of EGC is well-codified in the literature, however, a clear definition of AGC is required.

There are certain examples of heterogeneity in the definition of AGC in the literature, and the majority highlight an unclear or heterogeneous definition of AGC. A non-systematic search for studies that highlight a clear definition of AGC confirmed the lack of consistency for a definition of AGC in various research fields. The definitions of AGC generated in single studies are reported in Table II. The aim of the current study was to individually analyse all parameters of the TNM classification for AGC reported in each previous study. 
Table II. AGC definition in different studies.

First author, year (ref.)

Definition

Ott et al, 2003 (23)

Locally-advanced gastric cancer: cT3-4, N+ and M0

Locally-advanced disease: cT3-4, Nx and M0

Schuhmacher et al, 2001 (25)

Locally-advanced gastric cancer: Stages IIIA, IIIB and IV

Chiaravalli et al, 2001 (34)

Advanced cancers: From T2-T4; stages IB-IV

MacDonald et al, 2008 (35)

Advanced gastric cancer: From T2-4; from stage IB

Piso et al, 2000 (36)

Scaringi et al, 2008 (24)

Advanced tumour stages III-IV; less, stages I-II and more, stages III-IV

Locally-advanced gastric cancer: pT3-4, N+/- and M+/-

Luinetti et al, 1998 (28)

EGC: Gastric cancer that is limited to the mucosa or submucosa;

AGC: Cancer that has deeply invaded the gastric wall

Carboni et al, 2005 (27)

Advanced cases: T3-4 and $\mathrm{N}+$

Zilberstein et al, 2004 (37)

Early: $\mathrm{T} 1$ and any $\mathrm{N}$ and $\mathrm{M}$.

Advanced: T2-4 and any $\mathrm{N}$ and $\mathrm{M}$.

Doglietto et al, 2000 (38)

Advanced stage: Stage III

Piessen et al, 2009 (39)

Advanced stage: From T2; stages IIIB-IV

Soyuer et al, 2010 (40)

Locally-advanced: From T2; stages II-IV

Orditura, 2010 (30)

Locally-advanced gastric cancer: From T2; stage IIIA

Wirtz et al, 1998 (41)

Bataille et al, 2003 (26)

Theuer et al, 2002 (29)

Advanced carcinomas: pT2, pT3-4 and any N and M

Locally-advanced gastric carcinoma: cT3, cT4, N+ and $\mathrm{M}+$

Advanced stage: T2-3

AGC, advanced gastric cancer; EGC, early gastric cancer.

The definitions of AGC provided in the previous singular studies were compared with the current classifications of the Japanese Society of Gastric Cancer (15) using only the parameters for TNM classification. The results showed that only 5 studies resulted in a AGC T3 or T4 classification of the gastric neoplasms (23-27), whilst the remaining studies were hypothesised to be AGC neoplasms with parietal invasion initiating from stage T2 (Table III).

With regard to parameter N, all studies, with the exception of the studies by Ott et al (23), Scaringi et al (24), Luinetti et al (28), Carboni et al (27), Bataille et al (26) and Theuer et al (29), defined gastric neoplasias as AGC even in the absence of LN involvement (N0). By contrast, in the studies by Ott et al (23), Scaringi et al (24), Carboni et al (27), Orditura et al (30) and Bataille et al (26), LN involvement at a minimum of the N1 stage was required for the definition of AGC. Studies by Luinetti et al (28) and Theuer et al (29), however, defined AGC neoplasms as between T2 and T4, irrespective of the $\mathrm{N}$ parameter (Table IV).

Macroscopic classification of EGC and AGC is a simple and reliable method to prediction LN metastasis and determine the extent of LN dissection, unless endoscopic ultrasound (EUS) or CT scans show highly suspected LN metastasis.

All studies analysed in the current study, with the exception of those by Scaringi et al (24), Luinetti et al (28), Carboni et al (27) and Theuer et al (29), defined AGC as a gastric neoplasm irrespective of the presence or absence of metastasis (M1 or M0). The exceptions do not consider parameter $\mathrm{M}$ at all in the definition of AGC. The studies by Orditura et al (30) and Ott et al (23) clearly reported that they considered AGCs as neoplasias, even in the absence of metastases. Finally, a study by Bataille et al (26) reported M1 cases as AGCs.

In the Japanese Classification of Gastric Cancer (JCGC; 3rd English edition), stomach tumours are grouped by macroscopic classification into 2 types, superficial tumours (T1) and advanced tumours (T2-4) (15).

Superficial tumours, defined as type 0 are divided into 5 subtypes according to the Japanese Endoscopy Society Classification (1962; Table V), whereas AGC is divided into 5 types according to macroscopic appearance (Table VI). According to the Japanese Classification, stages Ia, Ib, IIa and IIb (T1a, T1b and N) are associated with EGC (Table VII).

In previous Japanese studies, AGC classification has been clear and univocal. By contrast, studies of other populations often exhibit heterogeneous definitions of AGC. Non-uniformity in the definition of AGC with regard to parameter $\mathrm{T}$ emerged from the studies analysed previously (Table III), with $11 / 16$ studies (68.7\%) considering that AGC started from T2, whilst 5/16 studies (31.2\%) considered the start from T3.

Non-homogeneity of the definition for AGC is more evident when considering the parameters $\mathrm{N}$ and $\mathrm{M}$. The definition prescinds from LN involvement or the presence of metastases. In the studies included in the current review, 9/16 were consistent with this definition of AGC. However, 5/16 (31.2\%) considered $\mathrm{N}+$ tumours as AGCs and 2/16 studies (12.5\%) did not evaluate $\mathrm{LN}$ involvement.

For parameter M, 9/16 studies (56.2\%) were consistent with the definition of AGC highlighted in Western studies, and such heterogeneity of the definition was reflected again in the assess- 


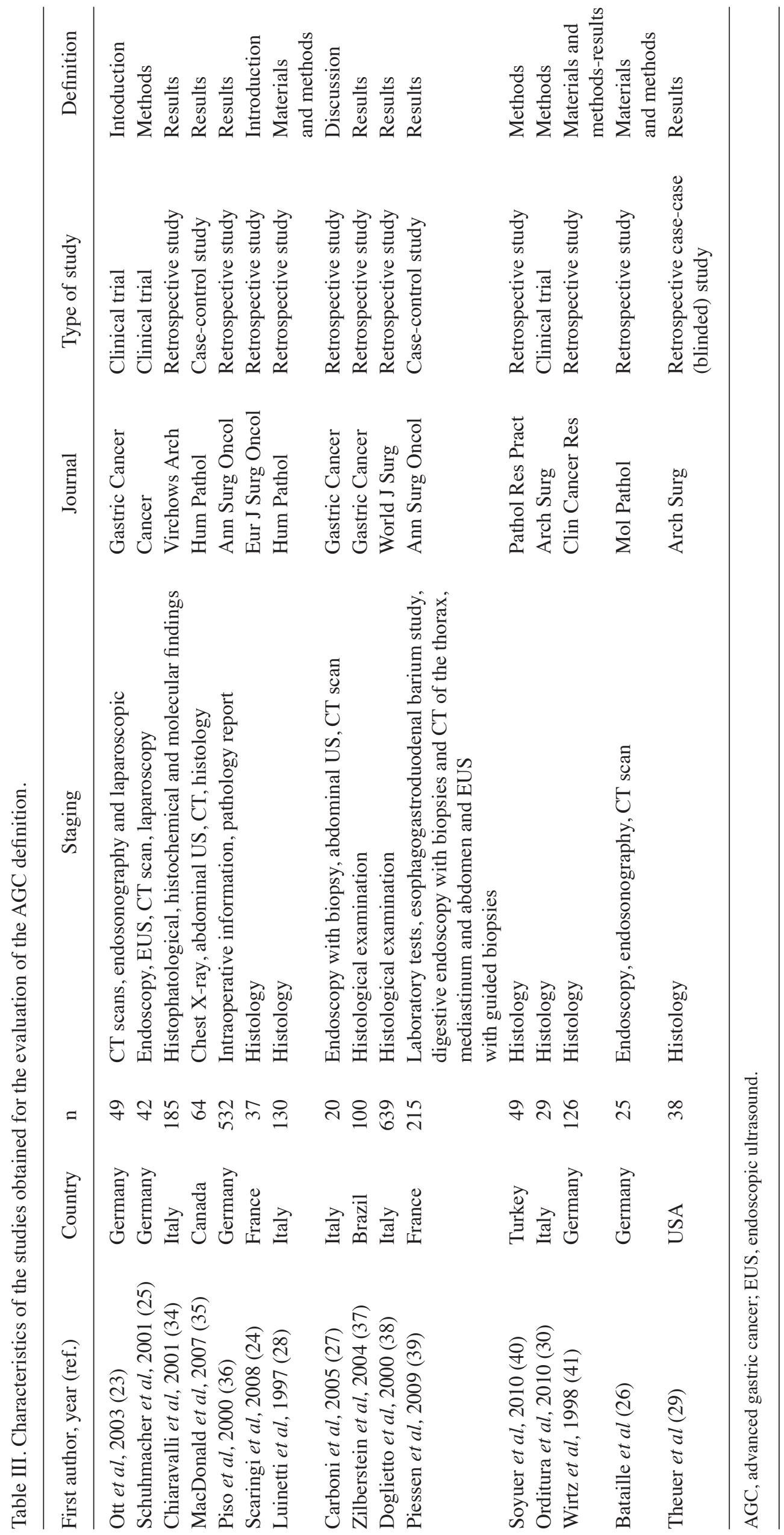


Table IV. TNM classification for study group C.

\begin{tabular}{|c|c|c|c|c|c|c|c|c|c|c|c|}
\hline First author, year (ref.) & $\mathrm{T} 1$ & $\mathrm{~T} 2$ & $\mathrm{~T} 3$ & $\mathrm{~T} 4$ & No & N1 & $\mathrm{N} 2$ & N3 & M0 & M1 & MX \\
\hline Ott et al, 2003 (23) & & & $\mathrm{X}$ & $\mathrm{X}$ & & $\mathrm{X}$ & $\mathrm{X}$ & $\mathrm{X}$ & $\mathrm{X}$ & & \\
\hline Schuhmacher et al, 2001 (25) & & & $\mathrm{X}$ & $\mathrm{X}$ & $\mathrm{X}$ & $\mathrm{X}$ & $\mathrm{X}$ & $\mathrm{X}$ & $\mathrm{X}$ & $\mathrm{X}$ & $\mathrm{X}$ \\
\hline Chiaravalli et al, 2001 (34) & & $\mathrm{X}$ & $\mathrm{X}$ & $\mathrm{X}$ & $\mathrm{X}$ & $\mathrm{X}$ & $\mathrm{X}$ & $\mathrm{X}$ & $\mathrm{X}$ & $\mathrm{X}$ & $\mathrm{X}$ \\
\hline MacDonald et al, 2008 (35) & & $\mathrm{X}$ & $\mathrm{X}$ & $\mathrm{X}$ & $\mathrm{X}$ & $\mathrm{X}$ & $\mathrm{X}$ & $\mathrm{X}$ & $\mathrm{X}$ & $\mathrm{X}$ & $\mathrm{X}$ \\
\hline Piso et al, 2000 (36) & & $\mathrm{X}$ & $\mathrm{X}$ & $\mathrm{X}$ & $\mathrm{X}$ & $\mathrm{X}$ & $\mathrm{X}$ & $\mathrm{X}$ & $\mathrm{X}$ & $\mathrm{X}$ & \\
\hline Scaringi et al, 2008 (24) & & & $\mathrm{X}$ & $\mathrm{X}$ & & $\mathrm{X}$ & $\mathrm{X}$ & $\mathrm{X}$ & & & \\
\hline Luinetti et al, 1998 (28) & & $\mathrm{X}$ & $\mathrm{X}$ & $\mathrm{X}$ & & & & & & & \\
\hline Carboni et al, 2005 (27) & & & $\mathrm{X}$ & $\mathrm{X}$ & & $\mathrm{X}$ & $\mathrm{X}$ & $\mathrm{X}$ & & & \\
\hline Zilberstein et al, 2004 (37) & & $\mathrm{X}$ & $\mathrm{X}$ & $X$ & $\mathrm{X}$ & $\mathrm{X}$ & $\mathrm{X}$ & $\mathrm{X}$ & $\mathrm{X}$ & $\mathrm{X}$ & \\
\hline Doglietto et al, 2000 (38) & & $\mathrm{X}$ & $\mathrm{X}$ & $\mathrm{X}$ & $\mathrm{X}$ & $\mathrm{X}$ & $\mathrm{X}$ & $\mathrm{X}$ & $\mathrm{X}$ & $\mathrm{X}$ & \\
\hline Piessen et al, 2009 (39) & & $\mathrm{X}$ & $\mathrm{X}$ & $\mathrm{X}$ & $\mathrm{X}$ & $\mathrm{X}$ & $\mathrm{X}$ & $\mathrm{X}$ & $\mathrm{X}$ & $\mathrm{X}$ & \\
\hline Soyuer et al, 2010 (40) & & $\mathrm{X}$ & $\mathrm{X}$ & $\mathrm{X}$ & $\mathrm{X}$ & $\mathrm{X}$ & $\mathrm{X}$ & $\mathrm{X}$ & $\mathrm{X}$ & $\mathrm{X}$ & \\
\hline Orditura et al, 2010 (30) & & $\mathrm{X}$ & $\mathrm{X}$ & $\mathrm{X}$ & & $\mathrm{X}$ & $\mathrm{X}$ & $\mathrm{X}$ & $\mathrm{X}$ & & \\
\hline Wirtz et al, 1998 (41) & & $\mathrm{X}$ & $\mathrm{X}$ & $\mathrm{X}$ & $\mathrm{X}$ & $\mathrm{X}$ & $\mathrm{X}$ & $\mathrm{X}$ & $\mathrm{X}$ & $\mathrm{X}$ & \\
\hline Bataille et al, 2003 (26) & & & $\mathrm{X}$ & $\mathrm{X}$ & & $\mathrm{X}$ & $\mathrm{X}$ & $\mathrm{X}$ & & $\mathrm{X}$ & \\
\hline Theuer et al, 2002 (29) & & $\mathrm{X}$ & $\mathrm{X}$ & $\mathrm{X}$ & & & & & & & \\
\hline
\end{tabular}

Table V. Subclassification of type 0 (10).

\begin{tabular}{ll}
\hline Type (location) & \multicolumn{1}{c}{ Example } \\
\hline 0-I (protruding) & Polypoid tumours \\
0-II (superficial) & $\begin{array}{l}\text { Tumours with or without } \\
\text { minimal elevation/depression } \\
\text { relative to surrounding mucosa }\end{array}$ \\
& Slightly elevated tumours \\
0-IIa (elevated) & $\begin{array}{l}\text { Tumours without } \\
\text { elevation/depression }\end{array}$ \\
0-IIb (flat) & Slightly depressed tumours \\
0-IIc (depressed) & Tumours with deep depression \\
0-III (excavated) &
\end{tabular}

ment of surgical outcome, choice of lymphadenectomy type and prognosis. It is difficult to standardise the results and outcome for survival if there is no conformity of the definition. Specific studies that do not take T2 into consideration for the classification of AGC substages. Consequently, results associated with chemotherapy and survival following surgery or the type of lymphadenectomy are likely to be false and incomparable.

The hypothesis that AGC starts from T3 leads to exclusion of $\mathrm{T} 2$ neoplasms from studies and is likely to modify the results. In addition, with regard to $\mathrm{LN}$ involvement and metastases, to consider only $\mathrm{M}+$ or $\mathrm{N}+$ as associated with AGC excludes N0 and M0 and leads to incomparable results.

In the context of such heterogeneity, it is impossible to use macroscopic classification since it is not certain that all studies identify neoplasms as starting from T2. Therefore, a number of studies incorrectly determine certain advanced neoplasms as early. In addition, other studies exclude neoplasms defined as advanced, therefore, making the interpretation of the results obtained difficult.

Table VI. Macroscopic types (10).

Type Classification

0 (superficial)

1 (mass)

2 (ulcerative)

3 (infiltrative ulcerative)

4 (diffuse infiltrative)

5 (unclassifiable)

Table VII. Stage groupings (10).

\begin{tabular}{lllll}
\hline Stages & N0 & N1 & N2 & N3 \\
\hline T1a (M), T1b (SM) & IA & IB & IIA & IIB \\
T2 (MP) & IB & IIA & IIB & IIIA \\
T3 (SS) & IIA & IIB & IIIA & IIIB \\
T4a (SE) & IIB & IIIA & IIIB & IIIC \\
T4b (SI) & IIIB & IIIB & IIIC & IIIC \\
M1 (any T and N) & IV & IV & IV & IV \\
\hline
\end{tabular}

M, musoca; SM, submucosa; MP, muscularis propria; SS, subserosa; SE, serosa; SI, adjacent structures.
Typical of T1 tumours.

Polypoid tumours, sharply demarcated from the surrounding mucosa.

Ulcerated tumours with raised margins surrounded by a thickened gastric wall without clear margins.

Ulcerated tumours with raised margins surrounded by a thickened gastric wall without clear margins.

Tumours without marked ulceration or raised margins, the gastric wall is thickened and indurated and the margin is unclear.

Tumours that cannot be classified into any of the additional types. 
The TNM classification was standardised in 2008. The AJCC Cancer Staging manual ( $7^{\text {th }}$ edition) (31) and the JCGC (3rd English Edition) (15) are comparable, with the only differences being with regard to the $\mathrm{M}$ parameter. In the AJCC classification, MX is excluded and M1 includes positive peritoneal fluid cytology. However, there are no differences between the two classifications with regard to staging. When the stage is used for analysis, a c-prefix must be added to specify that the stage is a clinically predicted stage, for example, analysis by TNM stage, including cT1N0, cT2-4N+ and cM1. The definition of EGC is extremely important for prognostic purposes and for the choice of therapeutic strategy, however, the principal classification used has been the TNM classification, with univocal results. Macroscopic classification is less used and often inconsistent with the definition highlighted by the Japanese Gastric Cancer Association (JGCA).

Therefore, we recommend standardisation of the definition for AGC. To correctly evaluate the results of the previous studies, the classification supplied by the JGCA must be used to guarantee homogeneity in the assessment of surgical outcomes. It is evident that a comprehensive systematic literature search must be performed for all studies that report a definition of ACG, in order to confirm the hypothesis and to subsequently identify a uniform definition of AGC to be used worldwide for the management of patients. The cTNM stages must be identified in the systemic review for a detailed description, as EUS or CT may now be utilised to pre-operatively evaluate $\mathrm{T}$ and $\mathrm{N}$ stage, although not always with $100 \%$ accuracy; therefore, the KLASS-01 study used 'stage 1' cancer as an indication (32).

\section{Conclusion}

The definition of EGC and AGC by macroscopic classification regardless of LN metastasis, is made when the tools to determine LN metastasis (EUS and high quality CT) are unavailable and gastroscopy and sonography become the most reliable methods for the evaluation of clinical stages. However, this has been an extremely useful definition for the determination of the treatment strategy and the prediction of LN metastasis and the prognosis. Although EUS and CT are capable of predicting LN metastasis (although not perfectly), the definition of EGC remains useful in a number of cases, since the majority of EGC do not exhibit LN metastasis.

Use of the term 'advanced' is more complicated compared with EGC, since it may be defined as: i) T2 or deeper cancer according to the Japanese classification; ii) a bulky tumour with LN enlargement compared with an 'early stage tumour'; iii) T4b (adjacent organ invading) tumour or unresectable tumour due to adjacent organ invasion or bulky LNs without distant metastasis, often referred to as 'locally advanced gastric cancer'; iv) M1 cancer +/- unresectable M0 cancer referred to as 'far advanced gastric cancer' in the majority of studies on palliative chemotherapy; or v) 'locally advanced gastric cancer', which may implicate 'resectable' cancer when compared with M1 'advanced' cancer (33).

Therefore, it may be difficult to differentiate between resectable advanced stage, unresectable M0 and M1 cancers using the term 'advanced'. It must be understood that 'advanced gastric cancer' may implicate a number of stages of disease and studies must highlight the exact clinical TNM stages for evaluation of the study.

\section{References}

1. International Agency for Research on Cancer: GLOBOCAN2008: Stomach cancer incidence, mortality and prevalence worldwide in 2008 summary. http://globocan.iarc.fr/factsheet.asp. Accessed February 25, 2013:

2. Coleman MP, Estève J, Damiecki P, Arslan A and Renard H: Trends in cancer incidence and mortality. IARC Sci Publ: 1-806, 1993.

3. Muir CS, Waterhouse J, Mack T, Powell J and Whelan S (eds): Cancer Incidence in Five Continents. Vol 5. IARC Scientific Publications no. 88. IARC Press, Lyon, 1987.

4. Parkin DM, Muir CS, Whelan SL, Gao YT, Ferlay J and Powell J (eds): Cancer Incidence in Five Continents. Vol 6. IARC Scientific Publications no. 120. IARC Press, Lyon, 1992.

5. Muñoz N and Asvall J: Time trends of intestinal and diffuse types of gastric cancer in Norway. Int J Cancer 8: 144-157, 1971.

6. Kram A, Peychewa M, Bachurska S and Domagala W: Morphometric distinction of signet-ring cell adenocarcinoma cells from foamy macrophages in gastric endoscopic biopsies. Pol J Pathol 62: 145-147, 2011.

7. Dziewulska-Bokiniec: Nowotwory narządów trawiennych In: Zarys Chirurgii Onkologicznej. Kopacz A (ed). Akademia Medyczna w Gdańsku, Gdańsku, p171,2000 (In Polish).

8. Krawczyk M (ed): Gastrointestinal Cancers. Vol 46. Wydawnictwo Lekarskie PZWL, Warsaw, pp153-155, 2001 (In Polish).

9. Godlewski J, Kuciel-Lisieska G, Licznerska G and Tenderenda M: Left-sided renal colic as a symptom of advanced stomach cancer - a case report. Wspolczesna Onkol 16: 191-193, 2012.

10. Ferlay J, Bray F, Pisani P, et al: GLOBOCAN 2000: Cancer incidence, mortality and prevalance worldwide, version 1.0 . IARC Cancer Base no. 5. IARC Press, Lyon, 2001.

11. Oota K and Sobin LH: Histological typing of gastric and oesophageal tumors. In: International Histological Classification of Tumours, no. 18. World Health Organisation, Geneva, 1977.

12. Borrmann R (ed): Tumors of the stomach and duodenum. In: Handbook of Specific Pathological Anatomy and Histology. Henke F and Lubarsch O (ed). Vol 4. Springer-Verlag, Berlin, p865, 1926 (In German).

13. Lauren P: The two histological main types of gastric carcinoma: Diffuse and so-called intestinal-type carcinoma. An attempt at a histo-clinical classification. Acta Pathol Microbiol Scand 64: 31-49, 1965.

14. Ming SC: Gastric carcinoma. A pathobiological classification. Cancer 39: 2475-2485, 1977.

15. Japanese Gastric Cancer Association: Japanese classification of gastric carcinoma: 3rd English edition. Gastric Cancer 14: 101-112, 2011.

16. Nakamura K, Ueyama T, Yao T, et al: Pathology and prognosis of gastric carcinoma. Findings in 10,000 patients who underwent primary gastrectomy. Cancer 70: 1030-1037, 1992.

17. Hirota T, Ming SC and Itabashi M (eds): Pathology of early gastric cancer. In: Gastric Cancer. Springer-Verlag, Tokyo, pp66-85, 1993.

18. Murakami T: Pathomorphological diagnosis. Definition and gross classification of early gastric cancer. Gann Monogr Cancer Res 11: 53-55, 1971.

19. Tsukuma H, Oshima A, Narahara $\mathrm{H}$ and Morii T: Natural history of early gastric cancer: a non-concurrent, long term, follow up study. Gut 47: 618-621, 2000.

20. Fenoglio-Preiser CM, Noffsinger AE, Belli J and Stemmermann GN: Pathologic and phenotypic features of gastric cancer. Semin Oncol 23: 292-306, 1996.

21. Ahn HS, Lee HJ, Yoo MW, et al: Changes in clinicopathological features and survival after gastrectomy for gastric cancer over a 20-year period. Br J Surg 98: 255-260, 2011.

22. Xue N, Huang P, Aronow WS, Wang Z, Nair CK, Zheng Z, Shen X, Yin Y, Huang F and Cosgrove D: Predicting lymph node status in patients with early gastric carcinoma using double contrast-enhanced ultrasonography. Arch Med Sci 7: 457-464, 2011.

23. Ott K, Sendler A, Becker K, et al: Neoadjuvant chemotherapy with cisplatin, 5-FU and leucovorin (PLF) in locally advanced gastric cancer: a prospective phase II study. Gastric Cancer 6: 159-167, 2003. 
24. Scaringi S, Kianmanesh R, Sabate JM, et al: Advanced gastric cancer with or without peritoneal carcinomatosis treated with hyperthermic intraperitoneal chemotherapy: a single western center experience. Eur J Surg Oncol 34: 1246-1252, 2008.

25. Schuhmacher CP, Fink U, Becker K, et al: Neoadjuvant therapy for patients with locally advanced gastric carcinoma with etoposide, doxorubicin and cisplatinum. Closing results after 5 years of follow-up. Cancer 91: 918-927, 2001.

26. Bataille F, Rümmele P, Dietmaier W, et al: Alterations in $\mathrm{p} 53$ predict response to preoperative high dose chemotherapy in patients with gastric cancer. Mol Pathol 56: 286-292, 2003.

27. Carboni F, Lepiane P, Santoro R, Mancini P, Lorusso R and Santoro E: Laparoscopic surgery for gastric cancer: preliminary experience. Gastric Cancer 8: 75-77, 2005.

28. Luinetti O, Fiocca R, Villani L, Alberizzi P, Ranzani GN and Solcia E: Genetic pattern, histological structure and cellular phenotype in early and advanced gastric cancers: evidence for structure-related genetic subsets and for loss of glandular structure during progression of some tumors. Hum Pathol 29: 702-709, 1998

29. Theuer CP, Campbell BS, Peel DJ, et al: Microsatellite instability in Japanese vs European American patients with gastric cancer. Arch Surg 137: 960-966, 2002

30. Orditura M, De Vita F, Muto P, et al: Adjuvant chemoradiotherapy in patients with stage III or IV radically resected gastric cancer: a pilot study. Arch Surg 145: 233-238, 2010.

31. Edge SB, Byrd DR, Compton CC, Fritz AG, Greene FL and Trotti A (eds): AJCC Cancer Staging Manual. 7th edition. Springer, New York, 2010.

32. Kim HH, Hyung WJ, Cho GS, et al: Morbidity and mortality of laparoscopic gastrectomy versus open gastrectomy for gastric cancer: an interim report - a phase III multicenter, prospective, randomized Trial (KLASS Trial). Ann Surg 251: 417-420, 2010.
33. Han S-K: Efficacy of laparoscopic subtotal gastrectomy with D2 lymph node dissection for locally advanced gastric cancer (KLASS-02-RCT). NCT01456598. http://clinicaltrials.gov/ct2/show/NCT0145659. Verified July, 2012.

34. Chiaravalli AM, Cornaggia M, Furlan D, Capella C, Fiocca R, Tagliabue G, Klersy C and Solcia E: The role of histological investigation in prognostic evaluation of advanced gastric cancer. Analysis of histological structure and molecular changes compared with invasive pattern and stage. Virchows Arch 439: 158-169, 2011

35. MacDonald WC, Owen DA and Le N: Chronic advanced gastric cancer: clinicopathologic analysis of survival data. Hum Pathol 39: 641-649, 2008.

36. Piso P, Werner U, Lang H, Mirena P and Klempnauer J: Proximal versus distal gastric carcinoma - what are the differences? Ann Surg Oncol 7: 520-525, 2000.

37. Zilberstein B, da Costa Martins B, Jacob CE, et al: Complications of gastrectomy with lymphadenectomy in gastric cancer. Gastric Cancer 7: 254-259, 2004.

38. Doglietto GB, Pacelli F, Caprino P, Sgadari A and Crucitti F: Surgery: independent prognostic factor in curable and far advanced gastric cancer. World J Surg 24: 459-463, 2000.

39. Piessen G, Messager M, Leteurtre E, Jean-Pierre $T$ and Mariette C: Signet ring cell histology is an independent predictor of poor prognosis in gastric adenocarcinoma regardless of tumoral clinical presentation. Ann Surg 250: 878-887, 2009.

40. Soyuer S, Soyuer I, Unal D, Ucar K, Yildiz OG and Orhan O: Prognostic significance of CD9 expression in locally advanced gastric cancer treated with surgery and adjuvant chemoradiotherapy. Pathol Res Pract 206: 607-610, 2010.

41. Wirtz HC, Müller W, Noguchi T, Scheven M, Rüschoff J, Hommel G and Gabbert HE: Prognostic value and clinopathological profile of microsatellite instability in gastric cancer. Clin Cancer Res 4:1749-1754, 1998. 